7. Reprod. Fert. (1972) 30, 173-175

\title{
PERIODIC ACID SCHIFF-POSITIVE MATERIAL IN HAMSTER PREIMPLANTATION EMBRYOS
}

\author{
H. D. MaREYNOLDS AND R. HADEK \\ Department of Histology, School of Dentistry, and \\ Department of Anatomy, Stritch School of Medicine, \\ Loyola University of Chicago, Maywood, Illinois 60153, U.S.A.
}

(Received 1st February 1972, accepted 17th February 1972)

Pyruvate is the central energy source for the developing mouse oocyte and zygote (Biggers, Whittingham \& Donahue, 1967) and for the two-cell stage embryo (Brinster, 1965), but glucose can be utilized as the sole energy source beginning at the eight-cell stage (Brinster \& Thomson, 1966). A histochemical study by Thomson \& Brinster (1966) has shown that glycogen is present in the ovulated mouse oocyte and increases in concentration until the blastocyst stage, when it almost completely disappears. Hence, these authors suggested that the polysaccharide is an energy source for the developing embryo. Since whole-mount preparations were employed in the histochemical study, and because the embryo enlarges between the 4th and 5th day, Ozias \& Weitlauf (1971) suggested that the total amount of glycogen may actually be the same but the opacity of the specimen may be reduced. In a correlative biochemical study, Stern \& Biggers (1968) confirmed that glycogen is synthesized during the first three cleavage divisions but claimed that there is only a slight decrease in the amount of the substance at the blastocyst stage. Although Ishida \& Chang (1965) localized succinic dehydrogenase activity in hamster ova, there is little other information concerning the metabolic activity of these embryos or the availability of energy sources. Thus, this study was undertaken to determine whether an endogenous supply of glycogen also exists in the hamster during preimplantation development.

Sexually mature male and female hamsters, Cricetus auratus, were placed together during late afternoon (one male with three females) and vaginal smears were taken the following morning to determine whether mating had taken place. Ovulation was assumed to have occurred between 02.00 and 05.00 hours (Yanagimachi \& Chang, 1964), and ages of the specimens were judged from this time. Inseminated females were killed at appropriate times and ova were flushed from the genital tract with physiological saline. The specimens collected included fertilized single-cell, two-cell, four-cell, eight-cell and sixteen-cell ova, as well as morula and blastocyst stages. Bouin's and Rossman's fluids were used to fix sections, and Tellyesnicky's fixative (Thomson \& Brinster, 1966) for whole-mount preparations. After oxidizing and staining by the periodic acid Schiff (PAS) method, all sections and whole-mount preparations were dehydrated in alcohol, passed through xylene and mounted 
with synthetic resin. Control slides were treated with $1.0 \%$ malt diastase (Nutritional Biochemicals) for $2 \mathrm{hr}$ at $37^{\circ} \mathrm{C}$ before periodic acid oxidation.

This study has shown that PAS-positive material is present in hamster preimplantation embryos from the fertilized zygote to the blastocyst stage. In each type of preparation, irrespective of whether it was a 5- $\mu \mathrm{m}$ section or a whole-mount, the intensity of the staining was approximately the same for all stages examined. All whole-mount preparations showed a heavy, intense reaction. Zonae pellucidae did not stain in these specimens since the structure was not preserved by Tellyesnicky's fixative. On the other hand, the sections showed a somewhat less heavy concentration of cytoplasmic PAS-positive material but intense staining was observed in the zonae pellucidae. The apparent difference in staining intensity between the cytoplasm of sections and whole-mount preparations is assumed to be due to the different thicknesses of the specimens.

Most of the cytoplasmic PAS-positive material in the sections of embryos is assumed to be glycogen because only slight staining was visible in sections of ova which had been previously treated with diastase. The PAS-positive, nonglycogen material is probably a glycoprotein because pyridine extraction (to remove glycolipids) did not reduce the staining and an attempt to stain compound lipids by the Sudan Black B method (H. D. McReynolds, unpublished observations) was not successful. Because zonae pellucidae stain equally well in control sections of ova, it is assumed that these structures are also largely glycoprotein. Apparently, Tellyesnicky's fixative does not preserve PASpositive material other than glycogen in the embryonic cells because wholemount preparations treated with diastase did not stain.

The failure to observe a significant difference in the amount of PAS-positive, diastase-labile material in any of the different stages of hamster preimplantation development may have been due to the following possibilities: (1) the histochemical method employed was not sensitive enough to detect possible quantitative changes in the concentration of the macromolecule, (2) glycogen was not utilized during hamster preimplantation development, or (3) glycogen was synthesized as quickly as it was utilized by the embryo. It is known, for example, that even though oxygen consumption increases sharply at the blastocyst stage in the mouse (Mills \& Brinster, 1967), glycogen is also being simultaneously synthesized from pyruvate and glucose by mouse blastocysts (Brinster, 1969). In the hamster, the amount of succinic acid dehydrogenase increases during cleavage, with the greatest concentration occurring at the blastocyst stage (Ishida \& Chang, 1965). This suggests expanded Krebs' cycle activity. Therefore, as in the mouse, it is possible that intermediate products of metabolism can be utilized during hamster preimplantation development for synthesis of glycogen de novo as well as for simultaneous Krebs' cycle activity. If glycogenolysis is also occurring, this could account for the seemingly static condition of glycogen during hamster preimplantation development observed in this study.

This investigation was supported by Public Health Service Research Grant HD 00552-08 from the National Institute of Child Health and Human Development and in part by the institutional GRSG grant. 


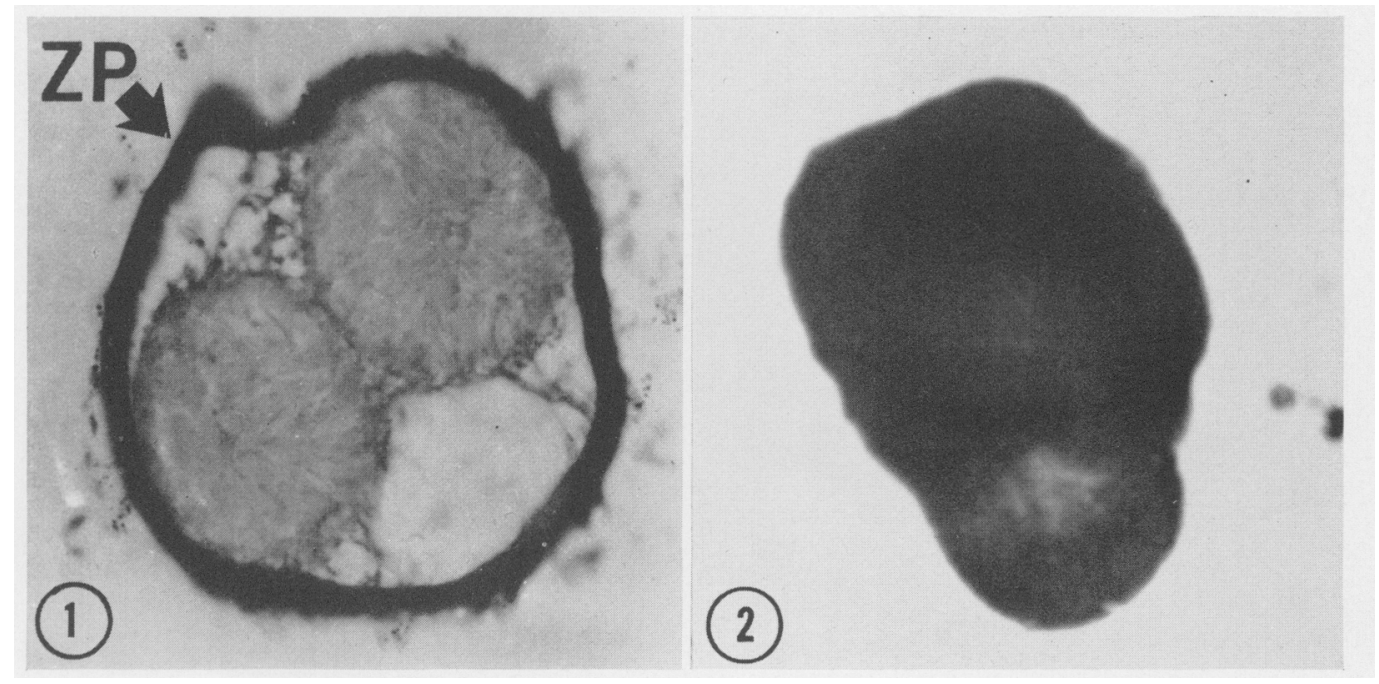

Fig. 1. Section of a two-cell hamster embryo which has been stained with the PAS method. The zona pellucida $(Z \mathbf{P})$ is deeply stained while the cytoplasmic reaction is less intense. $\times 375$.

FIG. 2. Whole-mount preparation of a hamster blastocyst preserved with Tellyesnicky's fixative. An intense PAS-positive reaction is present throughout most of the embryo. The somewhat less opaque area in the lower portion of the specimen is due to light passing through only two layers of trophoblast cells at the abembryonic pole. $\times 325$. 


\section{REFERENCES}

Biggers, J. D., Whittingham, J. D. \& Donahue, R. P. (1967) The pattern of energy metabolism in the mouse oocyte and zygote. Proc. natn. Acad. Sci. U.S.A. 58, 560.

BRINSTER, R. L. (1965) Studies on the development of mouse embryos in vitro. II. The effect of energy source. F. exp. Zool. 158, 59.

BRINSTER, R. L. (1969) Incorporation of carbon from glucose and pyruvate in the preimplantation mouse embryo. Expl Cell. Res. 58, 153.

Brinster, R. L. \& Thomson, J. L. (1966) Development of eight-cell mouse embryos in vitro. Expl Cell Res. 42, 308.

IshIDA, K. \& ChANG, M. C. (1965) Histochemical demonstration of succinic dehydrogenase activity in hamster and rabbit eggs. F. Histochem. Cytochem. 13, 470.

Mills, R. M. \& BRINSTER, R. L. (1967) Oxygen consumption of preimplantation mouse embryos. Expl Cell Res. 47, 337.

Ozias, C. B. \& Wertlauf, H. M. (1971) Hormonal influences on the glycogen content of normal and delayed implanting mouse blastocysts. F. exp. Zool. 177, 147.

Stern, S. \& BigGers, J. D. (1968) Enzymatic estimation of glycogen in the cleaving mouse embryo. J. exp. Zool. 168, 61 .

Thomson, J. L. \& BRINSTER, R. L. (1966) Glycogen content of preimplantation mouse embryos. Anat. Rec. 155, 97.

Yanagimachi, R. \& Chang, M. G. (1964) In vitro fertilization of golden hamster ova. F. exp. Zool. 156, 361. 